\title{
Decomposição estrutural da variação do rendimento do trabalho no brasil para os anos de 2005 e 2009
}

\author{
Structural decomposition of the variation of the labor compensation in Brazil for the years \\ 2005 and 2009
}

\begin{abstract}
Felipe César MarquesI, Guilherme Rubim Davoglio", Lina Tiemi SanadaIII, Marcia Regina Gabardo da Camara ${ }^{\text {IV }}$ e Umberto Antonio Sesso Filho ${ }^{\mathrm{V}}$
\end{abstract}

\begin{abstract}
Resumo
O objetivo do artigo é analisar a variação do rendimento médio do trabalho no Brasil entre os anos de 2005 e 2009 para diferentes setores da economia e níveis de qualificação. Para tanto, emprega-se a metodologia da decomposição estrutural, a partir dos dados coletados nas tabelas de insumo-produto e dos dados socioeconômicos para a economia brasileira presentes no World Input-Output Database. Os resultados encontrados revelam um aumento do rendimento médio real em $25,79 \%$ no período analisado. Dentro do fator tecnológico, o efeito de maior impacto foi o efeito intensidade, cujo comportamento foi instável entre os diferentes setores, gerando, em média, benefícios maiores entre os trabalhadores de menor qualificação. Na análise do fator de alteração da demanda final, o efeito preponderante foi o efeito volume da demanda final, que beneficiou de forma homogênea o rendimento do trabalho, seja para diferentes setores da economia, seja para diferentes níveis qualificação do trabalho.
\end{abstract}

Palavras chave: Decomposição Estrutural; Insumo-Produto; Rendimento do Trabalho

\begin{abstract}
The aim of the paper is to analyze the variation of the average labor compensation in Brazil betweens the years 2005 and 2009 to different sectors of the economy and different labor skills. In order to do so, it was applied the structural decomposition technique to the data from the input-output table and socio economic accounts relative to Brazilian economy, found on World Input-Output database. The results show an increase by $25.79 \%$ in average labor compensation for the period. From the technological factor, the most important effect was intensity factor, whose behavior was instable between different sectors, generating usually better benefits to low-skilled labor. As for the final demand variation factor, the predominant effect was the final demand volume effect, which created homogeneous benefits in labor compensation for both different sectors of the economy and different skilled labors.
\end{abstract}

Keywords: Structural Decomposition; Input-Output; Labor Compensation 


\section{Introdução}

Existem diversas razões pelas quais a desigualdade de renda necessita ser investigada e monitorada. Em primeiro lugar, a desigualdade de renda tem um impacto direto sobre o bem-estar social na medida em que as sociedades têm preferência por equidade. Além disso, a desigualdade de renda está diretamente relacionada ao nível de diversas variáveis sócio-econômicas importantes como, por exemplo, a taxa de poupança da economia, a taxa de mortalidade infantil e a extensão da pobreza. A dependência destas variáveis ao grau de desigualdade de renda existe na medida em que, as relações que as ligam à renda familiar per capita são não-lineares e, portanto, o nível médio dessas variáveis depende não só do nível médio da renda mas, também, de como ela se encontra distribuída.

Uma das características mais marcantes da economia brasileira é o seu elevado grau de desigualdade de renda. Tomando por exemplo o ano de 2004, o coeficiente de Gini foi de 0,564 no Brasil, o que o colocaria em décimo lugar no ranking dos países mais desiguais do mundo (Banco Mundial, 2005). No entanto, essa desigualdade vem diminuindo com o passar dos anos, pois o diferencial de remuneração entre os trabalhadores menos qualificados e aqueles de maior qualificação apresenta tendência declinante.

Os dois exemplos abaixo procuram ilustrar a forma não integrada como a questão da desigualdade tem sido tradicionalmente investigada no Brasil. Por um lado, Langoni (1973), em seu trabalho clássico sobre desigualdade de renda no Brasil estuda como a desigualdade de renda é gerada e revelada pelo mercado de trabalho a partir da heterogeneidade da força de trabalho com respeito ao nível educacional, idade, sexo, setor de atividade e região de residência. Ele chega à conclusão fundamental de que um dos principais determinantes da desigualdade de renda no Brasil são as disparidades educacionais entre os membros da força de trabalho. Estas disparidades educacionais, no entanto, não são simplesmente dadas mas, também, criadas pela sociedade brasileira. O autor, no entanto, não tenta identificar os determinantes da desigualdade educacional.

Por outro lado, o trabalho clássico de Mello e Souza (1979) sobre o financiamento da educação e acesso à escola no Brasil identifica, claramente, o papel das disparidades regionais em gastos em educação e da educação dos pais como os principais determinantes da desigualdade de educação da força de trabalho. Este autor, porém, não investiga quais as conseqüências da desigualdade de educação sobre a desigualdade de renda.

É possível identificar três períodos que são caracterizados por comportamentos distintos da desigualdade: de 1981 a 1989 , quando foram registrados contínuos aumentos no grau de desigualdade; 1989 a 1993, período caracterizado por um pico de desigualdade; e 1993 a 2004, onde foi observado um declínio quase contínuo da desigualdade (SOARES, 2006).

O objetivo deste artigo é avaliar os períodos posteriores aos observados anteriormente, mais precisamente, entre os anos de 2005 e 2009, a partir da decomposição estrutural de dados encontrados nas matrizes de insumo-produto e dos dados socioeconômicos para a economia brasileira presentes no World Input-Output Database (WIOD). Busca-se observar qual a evolução do rendimento médio para diferentes setores da economia ou, ainda, para diferentes níveis de qualificação do trabalho.

A metodologia empregada para atingir tais objetivos será a partir da teoria da decomposição estrutural, para verificar as causas da variação do rendimento médio do trabalho, dentre as qualificações baixa, média e alta, no Brasil para os anos de 2005 e 2009. Para tal finalidade, foi estimada a matriz de insumo-produto de Leontief que fornece informações econômicas para gerar conhecimentos empíricos. São três coeficientes calculados: coeficiente para alta qualificação (ch), coeficiente para média qualificação $(\mathrm{cm})$ e coeficiente para baixa qualificação $(\mathrm{cl})$ e, a partir deles, são feitas as análises cabíveis sobre o tema.

Os resultados indicam que o aumento no rendimento médio real observado foi de $25,79 \%$ no período analisado para os diferentes setores da economia. Ainda foi possível notar que, em média, os trabalhadores beneficiados foram aqueles que possuem uma menor qualificação.

O artigo é dividido em quatro seções além desta introdução: a segunda traz a revisão da literatura empírica e bibliográfica de trabalhos correlatos a esse, mostrando a importância da análise do tema proposto. A terceira falará sobre a metodologia utilizada, ou seja, todos os processos empregados para a obtenção dos resultados apresentados. Já a quarta seção mostra os resultados obtidos através da decomposição estrutural das matrizes de insumo-produto, enquanto a quinta, e última seção, faz as considerações finais acerca do trabalho.

\section{Revisão de Literatura}

Nesta seção serão analisadas as literaturas que trazem como foco o estudo da evolução da distribuição da renda, nos diferentes setores produtivos, no Brasil.

Os trabalhos pioneiros de Fishlow (1972) e Langoni (1973) estimularam o desenvolvimento de ampla literatura empírica a partir da análise das bases de dados do IBGE. Essa literatura inclui — mas não se restringe a — os trabalhos de Bonelli e Sedlacek (1989), Hoffman (1989), Ramos (1993), Barros e Mendonça (1996) e Ferreira e Litchfield (1996 e 1999). Alguns desses trabalhos visavam descrever com o maior rigor possível as tendências da evolução da distribuição de renda do país. Outros, a começar pelos dois trabalhos pioneiros, ambicionavam também explicar tal evolução, identificando os fenômenos ou estruturas econômicas que causariam os níveis e as mudanças na desigualdade brasileira. 
Em termos genéricos, as causas de uma distribuição desigual de renda devem pertencer a pelo menos cinco grupos, conceitualmente distintos de fatores. O primeiro é a existência de diferenças entre indivíduos no que diz respeito às suas características natas, como raça, gênero, inteligência e/ou riqueza inicial. Algumas dessas características — como a riqueza inicial - são observáveis, pelo menos a princípio. O segundo é a existência de diferenças entre indivíduos no que diz respeito a características individuais adquiridas, como nível educacional, experiência profissional etc. O terceiro grupo diz respeito aos mecanismos pelos quais o mercado de trabalho, principal canal de transformação das características individuais em renda, age sobre os dois grupos citados de características, transformando-as em diferenças no rendimento do trabalho (LAM; DURYEA, 1995, FERREIRA; BARROS, 1999).

O quarto grupo de fatores refere-se ao segundo grande grupo de mercados de fatores de produção, os mercados de capital. Na medida em que estes mercados sejam imperfeitos, apresentando, por exemplo, segmentação no acesso ao ou no preço do crédito, ou de apólices de seguros, e dado que seguros e crédito podem determinar a inserção do indivíduo em diferentes ocupações produtivas, ocorre que as imperfeições desses mercados também afetam a geração de renda e, portanto, sua distribuição. O quinto grupo de fatores é basicamente demográfico, incluindo decisões de formação de domicílio (matching), de fertilidade, de coabitação ou separação domiciliar ${ }^{1}$ (Lam e Duryea, 1995, Ferreira e Barros, 1999). Os fatores anteriormente destacados confirmam o fato de que nem toda desigualdade se deve a diferenças em escolaridade ou experiência.

O mercado de trabalho brasileiro é segmentado, principalmente, por setores produtivos e entre segmentos formais e informais. Assim, dois trabalhadores idênticos em suas características pessoais, mas um trabalhando num emprego formal e industrial e o outro num posto de trabalho informal na agricultura (ou no setor de serviços), terão remunerações bastante distintas. Neste exemplo, o primeiro trabalhador ganhará mais do que o outro, em função tão-somente das características do posto de trabalho ocupado. A segmentação regional também responde por sua parcela da desigualdade, mas, comparada com aquelas que lhe correspondiam nas decomposições não-parciais, sua importância é bastante menor. Isso se deve ao fato de que outros atributos, como o nível médio da educação, e a composição setorial da atividade produtiva variam substancialmente de uma região para outra (FERREIRA; LITCHFIELD, 2000).

A dominância temporária da visão de que o trade-off entre igualdade e eficiência (ou, em termos dinâmicos, crescimento) seria global, baseava-se numa interpretação direta das teorias de taxação ótima que previam que o imposto sobre a renda proveniente do trabalho (capital) reduziria o incentivo dos agentes para despender esforços no trabalho (a poupar), dada a redução no ganho marginal dessas atividades. Daí a recomendação, de forma alguma restrita ao Brasil, mas que aqui ganhou notoriedade com a exortação do então ministro Delfim Netto, de que se crescesse o bolo antes de dividi-lo. De acordo com essa lógica, ser campeão de desigualdade não seria necessariamente ruim, desde que isso levasse a altas taxas de crescimento agregado e, consequentemente, à redução da pobreza absoluta.

Ainda que o debate acadêmico sobre a natureza da relação entre desigualdade e crescimento esteja longe de ser resolvido, a opinião majoritária da profissão distanciou-se, durante a última década, daquela que acreditava num trade-off global entre desigualdade e eficiência. De fato, tanto os argumentos teóricos como a evidência empírica mais recente passaram, em grande parte, a sugerir uma relação causal negativa entre desigualdade e crescimento econômico. O principal argumento teórico por trás da hipótese de que a desigualdade reduz o crescimento é a consideração de que, com mercados imperfeitos de capital e sob assimetrias de informação, a desigualdade e a pobreza implicariam a existência de um grupo de agentes sem acesso ao crédito e, portanto, sem possibilidade de desenvolver projetos cujo valor privado (e social) é positivo. A inexistência ou imperfeição do mercado de crédito, violando os pressupostos dos teoremas de bem-estar baseados no equilíbrio geral à Arrow-Debreu, transformava a desigualdade de oportunidade em causa de ineficiência econômica (FERREIRA; LITCHFIELD, 2000).

O segundo argumento teórico que sugere a inexistência do trade-off global entre igualdade e crescimento foi o reconhecimento generalizado (por meio da chamada nova economia política) de que políticas econômicas não são formuladas por um "ditador benevolente". Ao contrário, elas são o resultado de um complexo processo político de tomada de decisões, que pode perder eficiência à medida que a sociedade se torna cada vez mais desigual (PERSSON; TABELLINI, 1994; ALESINA; RODRIK, 1994). A existência de conflitos sociais, seja dentro do parlamento que deve decidir sobre como responder a uma crise externa, seja em forma de um aumento da violência contra pessoas e propriedade, pode ter custos econômicos elevados e reduzir a eficiência da alocação global de recursos dentro de uma economia (BÉNABOU, 1996; RODRIK,1997). Ainda que o debate teórico e a apresentação de evidências e contra evidências empíricas continuem em andamento, já existe quase um consenso entre os economistas, brasileiros e estrangeiros, de que o efeito líquido do alto nível da desigualdade brasileira para o desenvolvimento do país é negativo.

Observando a dinamicidade de mercados, sejam eles de bens e serviços, financeiros ou de trabalho, nota-se que algo significativo mudou nos últimos 30 anos nas sociedades capitalistas que se reorganizam e se reestruturam no sentido de introduzir

1 A importância desses fatores para a determinação da renda familiar per capita é conceitualmente óbvia: considerem-se, por exemplo, duas sendo porém que, na primeira, casais tendem sociedades com distribuições de renda por preceptor idênticas, a formar-se entre pessoas ricas e pobres, enquanto que, na segunda, o homem mais rico tende a "casar-se" com a mulher mais rica, e assim por diante. As distribuições de renda familiar per capita serão claramente distintas, com a segunda sociedade apresentando, caeteris paribus, um maior nível de desigualdade. Empiricamente, a importância dos fatores demográficos para a distribuição de renda brasileira é amplamente confirmada (LAM; DURYEA, 1995,

FERREIRA; BARROS, 1999). 
novas formas de racionalização do trabalho e da vida social.

Esse parece ser o único ponto comum no intenso debate que acompanha o esforço para compreender o processo observado há 30 anos, mas ainda em curso (ARRIGHI, 1997; HARVEY, 1992, p.176); mesmo que, para alguns, essas mudanças signifiquem tão-somente a intensificação de um processo observado desde os primórdios do próprio capitalismo, questionando os aspectos ideológicos das novas formas de racionalização aplicadas (POLLERT, 1988; SAYER, 1989 apud HARVEY, 1992).

A estrutura do mercado de trabalho tem passado por mudanças: altas taxas de desemprego são acompanhadas da crescente insegurança e precariedade das novas formas de ocupação. A flexibilização da força de trabalho (contratos de tempo parcial, subcontratação, terceirização, entre outros fatores) inscreve-se no mesmo processo que articula o discurso por maiores níveis de qualificação para os trabalhadores que permanecem empregados e ocupam postos de trabalho considerados essenciais para os processos produtivos nos quais se inserem (SEGNINI, 2000).

A desigualdade de renda nos diversos setores produtivos da economia mostra o mesmo padrão - desigualdade muito alta em meados do governo Geisel (1974-1979) e posterior queda, não obstante permaneça em nível considerado alto. Estes oscilam em um padrão mais ou menos estável até 1986, seguidos de fortes oscilações no período da hiperinflação. A volta à estabilidade se dá em patamares mais altos que durante o início da década de 1980, e a partir de 2001 há uma queda forte e potencialmente sustentada. É notável que para todas as medidas usadas o ano 2004 é o menos desigual, até então medido pela Pnad (SOARES, 2006).

Cabe ainda citar a política de valorização do salário mínimo, que pode ter contribuído para a crescente salarial dos profissionais menos qualificados. Nos últimos anos tem havido uma tênue, porém perceptível queda na desigualdade no Brasil (FERREIRA et al. 2006). Barros et al. (2006) quantificam a importância dos fatores demográficos, de alterações no mercado de trabalho e dos programas de transferência social. Firpo e Reis (2006) focam sua preocupação no papel do salário mínimo na desigualdade de renda no Brasil, no período 1992-2004 e verificam que durante o período de inflação mais elevada o salário mínimo teve importante papel na redução da desigualdade.

Uma outra linha de trabalhos ainda diz que há uma possível relação entre a evolução do salário mínimo e os níveis de pobreza no país. Barros et al. (2000) utilizam uma análise de equilíbrio geral e encontram relação positiva entre aumentos no salário mínimo e redução na pobreza, quando são levados em conta os efeitos sobre os benefícios previdenciários.

\section{Metodologia}

Esta seção descreve como os dados analisados foram obtidos e o tipo de tratamento recebido, assim como a metodologia utilizada neste trabalho. Os dados foram obtidos no banco de dados do WIOD (World Input-Output Database). Foram utilizadas as variáveis de compensação do trabalho e de horas trabalhadas dos anos de 2005 e de 2009, ambas subdivididas em alta, média e baixa qualificação. Para estes valores foi utilizado o deflator de valor agregado. Também foi utilizada a matriz de Insumo e Produto do Brasil, na qual foi utilizada o deflator de insumos intermediários.

De acordo com a classificação metodológica do WIOD, o trabalho de baixa qualificação inclui: educação elementar (primário); regular do ensino fundamental ou do primeiro grau; educação de jovens e adultos, supletivo do ensino fundamental ou do primeiro grau; alfabetização de jovens e adultos; creche; classe de alfabetização; maternal, jardim de infância. Média qualificação engloba o ensino médio dos primeiros e segundos ciclos; aluno regular do ensino médio ou do segundo grau; educação de jovens e adultos, supletivo de ensino médio ou do segundo grau. Por fim, a alta qualificação agrega educação superior (graduação, mestrado e doutorado).

A análise da decomposição estrutural tem sido utilizada para verificação das causas da variação do emprego no Brasil. Kupfer e Freitas (2004) analisaram a década de 1990 no quesito do emprego no país utilizando esta decomposição. Os autores observaram uma expansão de milhões de postos de trabalhos para o período observado.

Sesso Filho et al (2010) analisaram a variação do emprego com a mesma metodologia para o período de 1993 a 2003 . Neste caso verificou-se um deslocamento dos postos de trabalho, dos setores agropecuário e industrial para comércio e serviços, com aumento do número total de pessoas ocupadas (7,3 milhões). Ymai (2010) analisou as principais fontes de variação no emprego e na renda a partir de 1990 no Brasil, tendo destaque no impacto tecnológico no emprego, com base da metodologia de decomposição estrutural.

Este artigo utiliza a metodologia de Sesso Filho et al (2010) para executar a decomposição estrutural e mostrar a variação do salário (rendimento) médio dentre as qualificações (baixa, média e alta) e os setores no Brasil.

Leontief (1983) esquematizou a matriz insumo-produto a partir da noção que o produto de cada setor é também insumo para outro setor da economia dentro de uma cadeia produtiva. Ou seja, compras e vendas são observações equivalentes. Assim, a matriz insumo-produto fornece informações econômicas de forma a gerar conhecimentos empíricos.

Assim, a matriz insumo-produto pode ser obtida por:

$$
I L=(I-A)^{-1}
$$


A Equação (1) diz respeito às matrizes, onde IL é a produção total, e $(1-A)^{-1}$ é a matriz inversa de Leontief, também conhecida como a matriz de coeficientes técnicos de insumos diretos e indiretos. A matriz de insumo-produto de Leontief é utilizada como base para a decomposição, levando em consideração que as variações nos rendimentos do trabalho seguem uma função linear do crescimento econômico.

A matriz A é obtida através do consumo intermediário (CI), multiplicado pela matriz inversa da matriz diagonal da produção (PROD):

$$
A=C I^{*}(\operatorname{Diag}(P R O D))^{-1}
$$

Os coeficientes das variáveis podem ser calculados pelo mesmo princípio da matriz A, contudo, baseado no rendimento (REND) de cada qualificação. São três coeficientes calculados: coeficiente para alta qualificação (ch), coeficiente para média qualificação $(\mathrm{cm})$ e coeficiente para baixa qualificação $(\mathrm{cl})$.

$$
\begin{aligned}
& h=R E N D H^{*}(\operatorname{Diag}(P R O D))^{-1} \\
& c m=R E N D M^{*}(\operatorname{Diag}(P R O D))^{-1} \\
& c l=R E N D L^{*}(\operatorname{Diag}(P R O D))^{-1}
\end{aligned}
$$

Seja y o total da demanda final por categoria, que pode ser obtido através da soma da demanda final (F):

$$
y=\operatorname{soma}(F)
$$

Desta forma, é possível calcular o coeficiente da demanda final por categoria (DF):

$$
D F=F^{*}(\operatorname{Diag}(y))^{-1}
$$

Esses cálculos foram realizados tanto para o ano de 2005, quanto para o ano de 2009. Para a decomposição estrutural de cada categoria de classificação segue o cálculo abaixo:

$$
\begin{aligned}
& A H=0,5 * \operatorname{Diag}\left(\mathrm{ch}^{\prime}-\mathrm{ch}\right) *\left(I L{ }^{\prime} * D F^{\prime} * y^{\prime}+I L * D F^{*} y\right) \\
& B H=0,5 * \operatorname{Diag}\left(c^{\prime}\right) * I L{ }^{\prime} *\left(A^{\prime}-A\right) * I L * D F * y+\operatorname{Diag}(\mathrm{ch}) * I L *\left(A^{\prime}-A\right) * I L{ }^{\prime} * D F^{*} y^{\prime} \\
& C H=0,5 * \operatorname{Diag}\left(c^{\prime}\right) * I L^{\prime} *\left(D F^{\prime}-D F\right) * y+\operatorname{Diag}(\mathrm{ch}) * I L^{*}\left(D F^{\prime}-D F\right) * y^{\prime} \\
& D H=0,5^{*} \operatorname{Diag}\left(\mathrm{ch}^{\prime}\right) * I L^{\prime} * D F^{\prime}+\operatorname{Diag}(\mathrm{ch}) * I L^{*} D F^{*}\left(y^{\prime}-y\right) \\
& A M=0,5^{*} \operatorname{Diag}\left(\mathrm{cm}^{\prime}-\mathrm{cm}\right) *\left(I L{ }^{\prime} * D F^{\prime} * y^{\prime}+I L^{*} D F^{*} y\right) \\
& B M=0,5 * \operatorname{Diag}\left(\mathrm{cm}^{\prime}\right) * I L^{\prime} *\left(A^{\prime}-A\right) * I L^{*} D F^{*} y+\operatorname{Diag}(\mathrm{cm}) * I L^{*}\left(A^{\prime}-A\right) * I L{ }^{\prime} * D F^{*} y^{\prime} \\
& C M=0,5 * \operatorname{Diag}\left(\mathrm{cm}^{\prime}\right) * I L^{\prime} *\left(D F^{\prime}-D F\right) * y+\operatorname{Diag}(\mathrm{cm}) * I L^{*}\left(D F{ }^{\prime}-D F\right) * y^{\prime} \\
& D M=0,5 * \operatorname{Diag}\left(\mathrm{cm}^{\prime}\right) * I L^{\prime} * D F^{\prime}+\operatorname{Diag}(\mathrm{cm}) * I L^{*} D F^{*}\left(y^{\prime}-y\right) \\
& A L=0,5 * \operatorname{Diag}\left(\mathrm{cl}^{\prime}-\mathrm{cl}\right)^{*}\left(I L{ }^{\prime} * D F^{\prime} * y^{\prime}+I L * D F^{*} y\right) \\
& \left.B L=0,5 * \operatorname{Diag}(\mathrm{cl})^{\prime}\right) * I L^{\prime} *\left(A^{\prime}-A\right) * I L * D F * y+\operatorname{Diag}(\mathrm{cl}) * I L *(A '-A) * I L{ }^{\prime} * D F * y \text { ' } \\
& C L=0,5 * \operatorname{Diag}\left(c^{\prime}\right) * I L^{\prime} *\left(D F^{\prime}-D F\right) * y+\operatorname{Diag}(c l) * I L^{*}\left(D F^{\prime}-D F\right)^{*} y^{\prime} \\
& D L=0,5 * \operatorname{Diag}\left(\mathrm{cl}^{\prime}\right) * I L^{\prime} * D F^{\prime}+\operatorname{Diag}(\mathrm{cl}) * I L^{*} D F^{*}\left(y^{\prime}-y\right)
\end{aligned}
$$

As Equações (6), (7) e (8) dizem respeito à decomposição dos fatores de alteração dos rendimentos médios do trabalho para cada um dos níveis de qualificação: alto, médio e baixo, respectivamente. As variáveis com o sobrescrito aspas simples (“" “) referem-se os dados calculados para o ano de 2009.

A interpretação dos resultados para os rendimentos de alta qualificação pode ser realizada da seguinte maneira: o efeito intensidade (chamado de AH na equação (6)) refere-se às variações no rendimento do trabalho de alta qualificação provocado pela intensificação da utilização do fator no processo produtivo (produtividade dos rendimentos); o efeito tecnológico (BH) diz respeito às alterações observadas nos rendimentos do trabalho qualificado decorrentes de alterações nos coeficientes técnicos das matrizes entre os anos estudados. Para fins de análise, estes dois efeitos foram agrupados sob a denominação "fator tecnológico".

$\mathrm{O}$ efeito estrutura da demanda final $(\mathrm{CH})$ final corresponde ao impacto das modificações na demanda final sobre o rendimento do trabalho entre os diferentes setores avaliados; já o efeito volume da demanda final (DH) avalia os impactos do crescimento econômico (crescimento da demanda final) sobre o rendimento do trabalho qualificado para diferentes setores da economia. Sem perda de generalidade, os efeitos estrutura da demanda final e volume da demanda final são agregados como "fator de alteração da demanda final". A interpretação dos efeitos para os rendimentos de baixa e média qualificação podem 
ser feitos de forma análoga.

A formulação das equações acima é apenas uma das situações possíveis de serem descritas. Segundo Dietzenbacher e Hoekstra (2000), com n fatores, é possível a ocorrência de n! formas de decomposição estrutural.

\section{Resultados e Discussão}

A análise inicial dos resultados revela que durante a segunda metade da década de 2000 , o rendimento médio real do trabalho no Brasil obteve um aumento de 25,79\%, passando de $\mathrm{R} \$ 6,55 /$ hora a $\mathrm{R} \$ 8,24 /$ hora. A observação mais detalhada dos dados apresenta diferentes resultados para os três extratos de qualificação levantados no trabalho. O grupo que mais se beneficiou com o aumento dos rendimentos do trabalho foi o de baixo grau de qualificação, cujo valor recebido por hora saltou, em média, 29,87\%; em seguida, o grupo de qualificação média obteve aumentos, em média, de 20,52\%, e por fim, os trabalhadores mais qualificados obtiveram aumento médio de $8,76 \%$. Estes resultados podem ser mais bem visualizados na Tabela 1 .

Tabela 1 - Variação do rendimento médio do trabalho no Brasil, segundo grau de especialização, 2005-2009

\begin{tabular}{l|c|c|c}
\hline Qualificação & $R \$ / h r 2005$ & $R \$ / h r 2009$ & Variação \\
\hline Alta & 15,36 & 16,70 & $8,76 \%$ \\
\hline Média & 5,98 & 7,21 & $20,52 \%$ \\
\hline Baixa & 4,37 & 5,68 & $29,87 \%$ \\
\hline Total & 6,55 & 8,24 & $25,79 \%$ \\
\hline
\end{tabular}

Fonte: Elaboração própria, com base nos dados de WIOD (2016)

A estratificação dos dados entre os setores da economia também apresenta diferentes comportamentos intersetoriais. Alguns setores apresentaram grande incremento nos rendimentos médios, como é o caso de Hotéis e Restaurantes, com variação de 96,79\% e atividades imobiliárias ( $84 \%$ de crescimento). Por outro lado, setores como Educação e Coque, Refino de Petróleo e

Figura 1 - Variação do rendimento médio do trabalho no Brasil entre 2005 e 2009, por setor

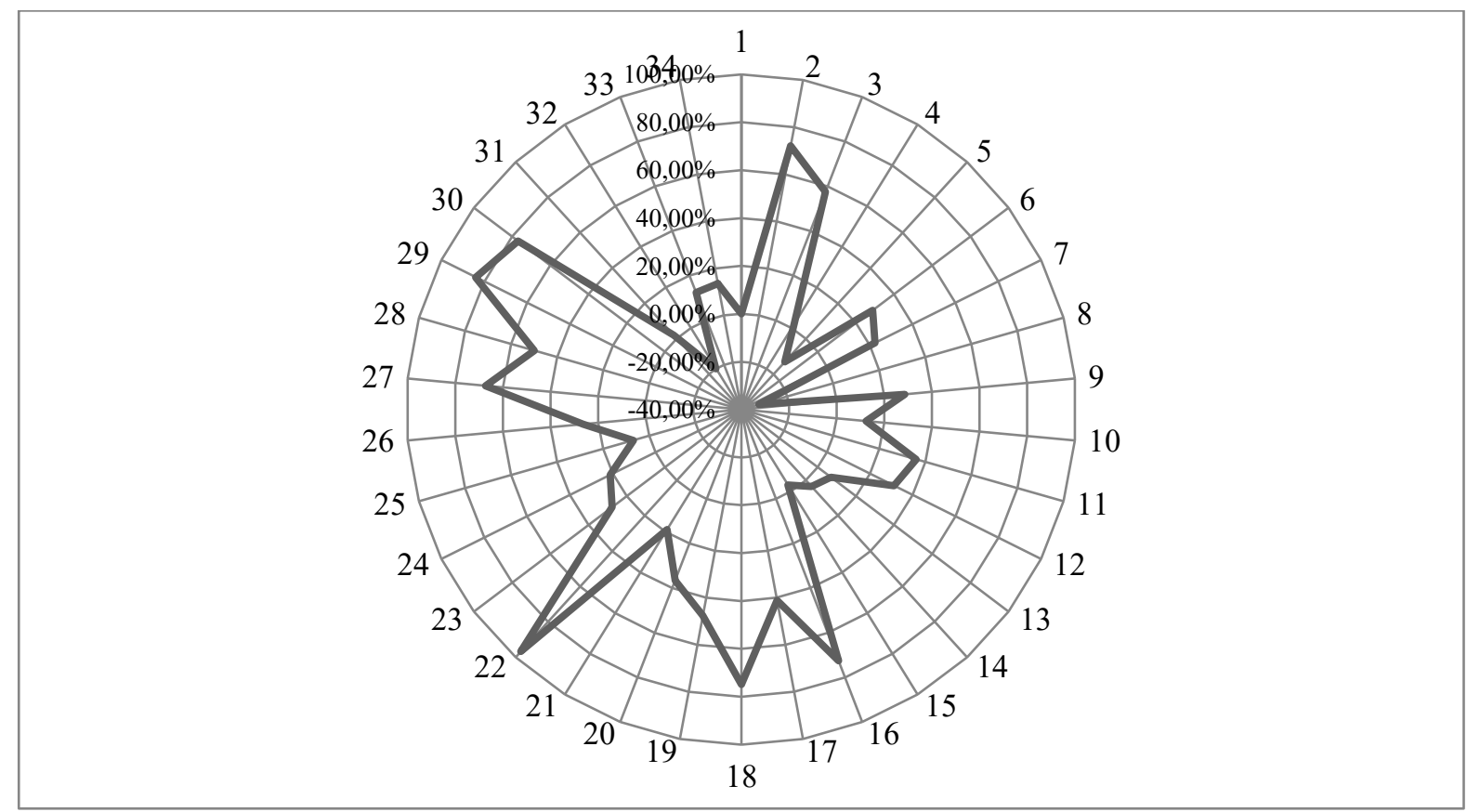

Fonte: Elaboração própria, com base nos dados de WIOD (2016) 
Combustível Nuclear sofreram quedas significativas (-19,92\% e -32,39\%, respectivamente). Para facilitar a visualização dos resultados, foi atribuído a cada setor um valor numérico específico, apresentado no Anexo 1. Aponta-se em seguida, a variação dos rendimentos médios para todos os setores analisados, na Figura 1.

A análise setorial, juntamente com a estratificação por especialização, revela que de um modo geral, os rendimentos para diferentes qualificações intrassetoriais apresentaram a mesma tendência, diferenciando-se pela intensidade das variações, com predomínio de aumento dos rendimentos na classe dos trabalhadores menos qualificados. À guisa de exemplo, o setor de Metais Básicos e Metais Fabricados (setor número 12) apresentou ganho de rendimento para todos os níveis de qualificação, sendo este, porém, muito mais sutil entre os trabalhadores de qualificação alta $(6,14 \%)$, enquanto o rendimento daqueles de qualificação média e baixa aumentou em $22,89 \%$ e $50,18 \%$, respectivamente. A variação dos rendimentos médios para todos setores e níveis de especialização é apresentada na Figura 2.

Figura 2 - Variação do rendimento médio do trabalho no Brasil entre 2005 e 2009, por setor, segundo nível de qualificação

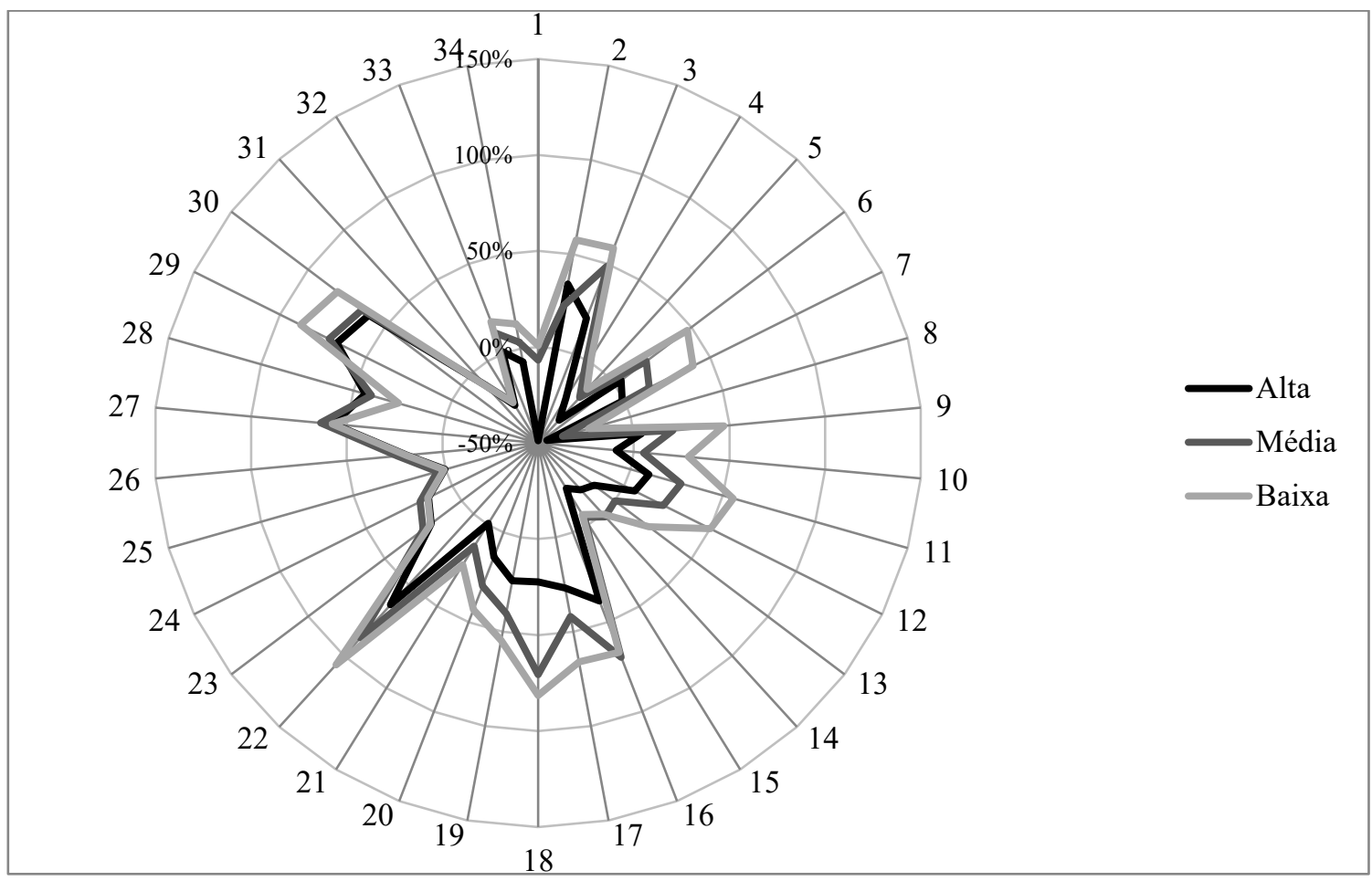

Fonte: Elaboração própria, com base nos dados de WIOD (2016)

Aprofundando mais o objeto de estudo, é possível traçar os efeitos que explanam a variação dos rendimentos do trabalho, decompondo-os em dois fatores: um relacionado à alteração tecnológica, composto pelo efeito intensidade e pelo efeito tecnológico, e um fator de alterações na demanda final, composto pelo efeito estrutura da demanda final e pelo efeito volume da demanda final.

Entre os trabalhadores mais qualificados observa-se que em 20 setores o fator tecnológico foi predominantemente negativo, embora os dados tenham apresentados grande amplitude (entre queda de - $60,48 \%$ para o setor de Coque, Refino de Petróleo e Combustível Nuclear - setor 8 - a aumento de 68,66\% em Atividades Imobiliárias - setor 29). O efeito tecnológico, em via de regra, apresentou comportamento mais estável, muitas vezes sem ultrapassar variação de $2 \%$ e, portanto, o efeito intensidade apresentou-se como o de maior influência dentro do fator tecnológico. Em outras palavras, a alteração da intensidade em trabalho qualificado provocou forte alteração no rendimento dos trabalhadores de alta qualificação, na maior parte delas, de forma negativa (o ganho de produtividade dos rendimentos provoca uma queda na razão rendimento por hora / produto). O resultado para todos os setores é mostrado na Figura 3.

Por outro lado, o fator demanda foi majoritariamente positivo, e com menor sensibilidade nos resultados (Figura 4). Para a maior parte dos setores o efeito volume da demanda final ultrapassou o efeito estrutura da demanda final, indicando que o crescimento vivido pelo país na última metade da década de 2000 impulsionou o ganho dos rendimentos do trabalho de maneira conjunta, enquanto o fator tecnológico, especialmente o efeito intensidade, foi o responsável pelas diferenças intersetoriais. 
Figura 3 - Impacto do fator tecnológico na variação do rendimento dos trabalhadores de alta qualificação no Brasil entre 2005 e 2009 , por setor

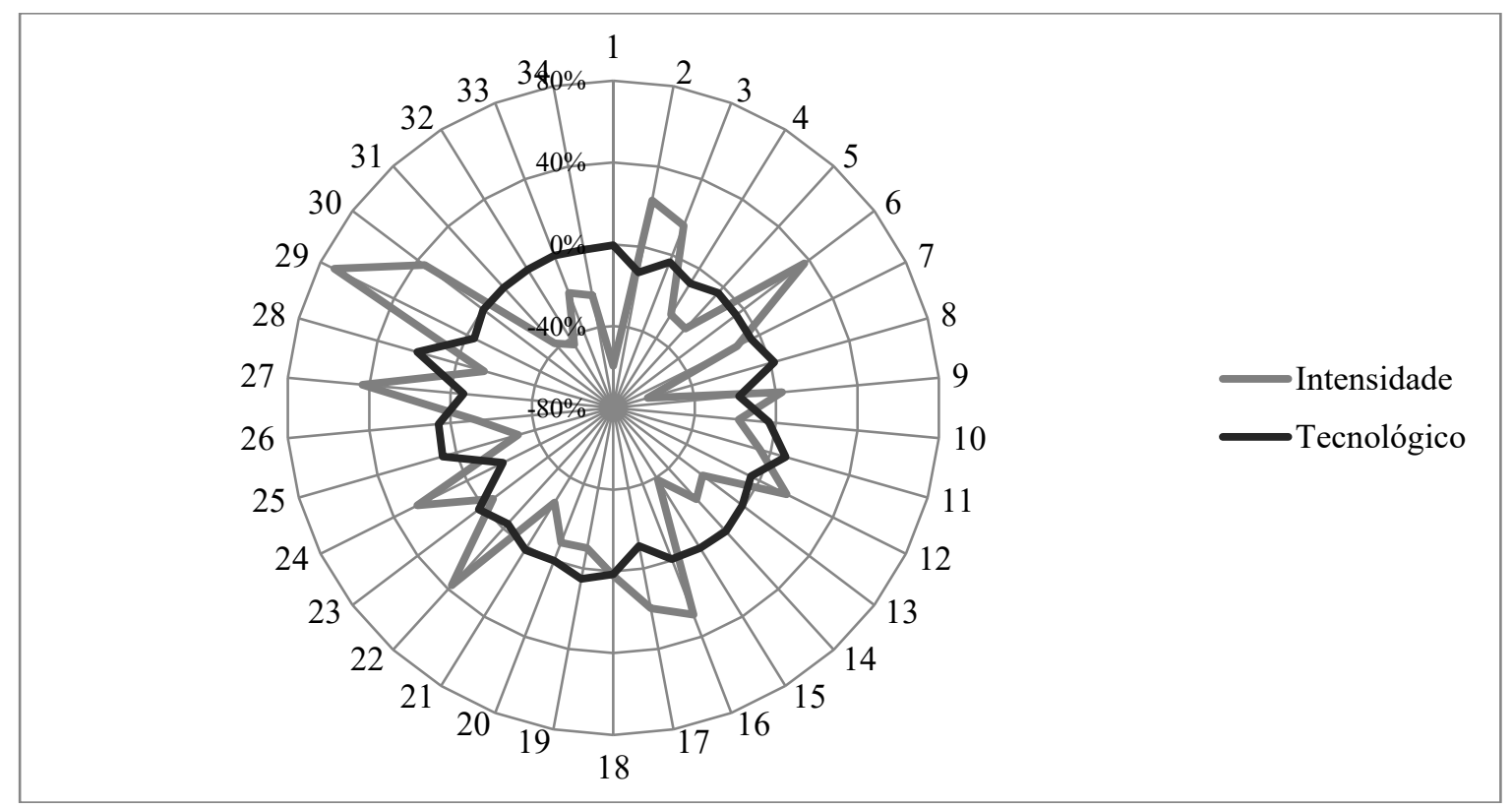

Fonte: Elaboração própria, com base nos dados de WIOD (2016)

Figura 4 - Impacto do fator demanda na variação do rendimento dos trabalhadores de alta qualificação no Brasil entre 2005 e 2009, por setor

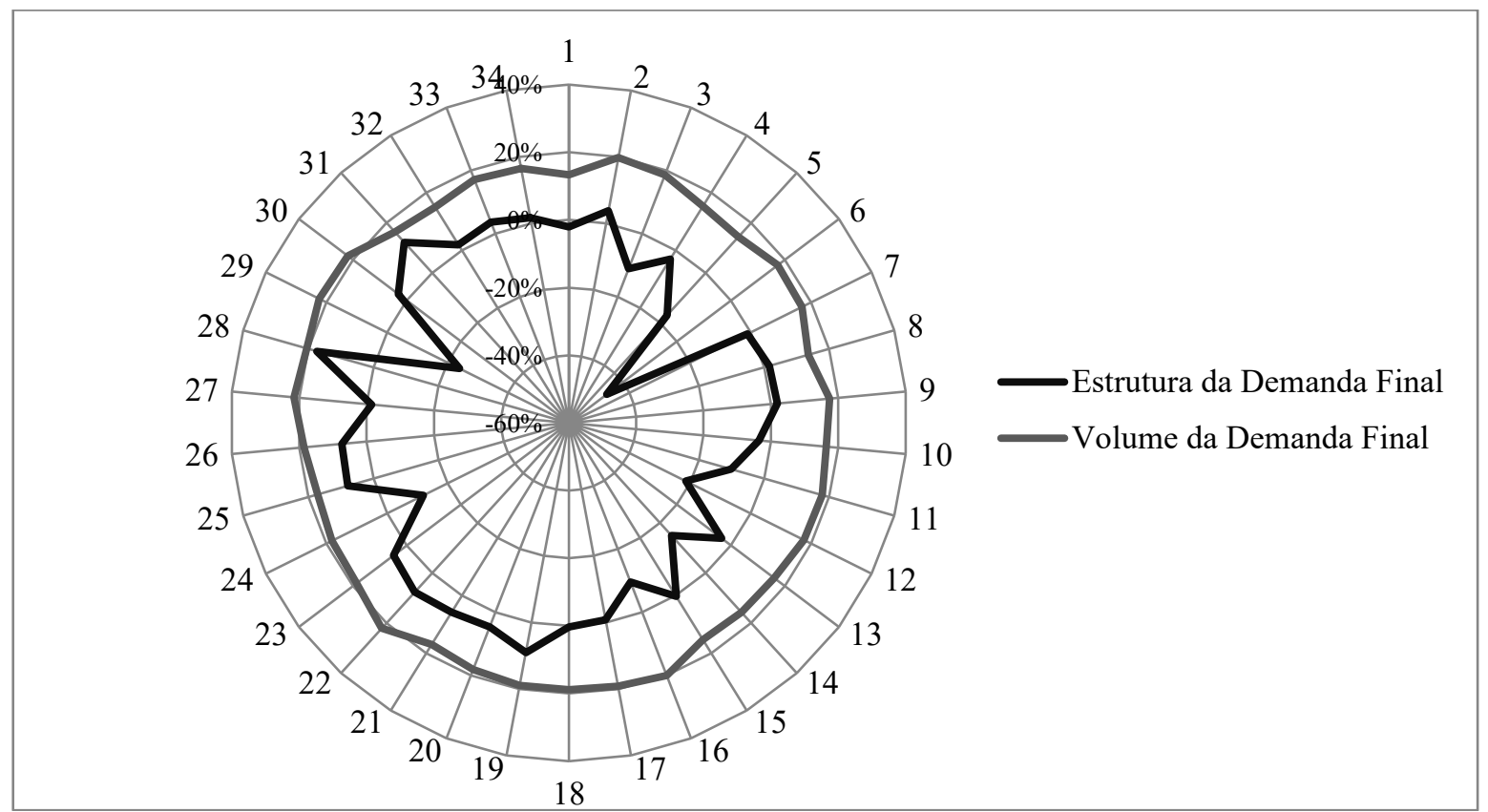

Fonte: Elaboração própria, com base nos dados de WIOD (2016)

Entre os trabalhadores de qualificação média, o impacto negativo do fator tecnológico foi ligeiramente menor, isto é, 17 dos 34 setores avaliados apresentaram queda nos rendimentos devido a mudanças na estrutura tecnológica, ainda que, mais uma vez, a amplitude dos dados tenha sido relevante (-52,59\% para o setor Coque, Refino de Petróleo e Combustível Nuclear e 73,18\% em Atividades Imobiliárias). Tal como entre os trabalhadores de maior qualificação, o efeito intensidade foi majoritariamente superior ao efeito tecnológico, enquanto este apresenta comportamento mais homogêneo, evidenciando baixa 
alteração nos coeficientes técnicos no período de análise. A relação completa do impacto do fator tecnológico nos rendimentos dos trabalhadores de qualificação média é apresentada na Figura 5.

Figura 5 - Impacto do fator tecnológico na variação do rendimento dos trabalhadores de qualificação média no Brasil entre 2005 e 2009 , por setor

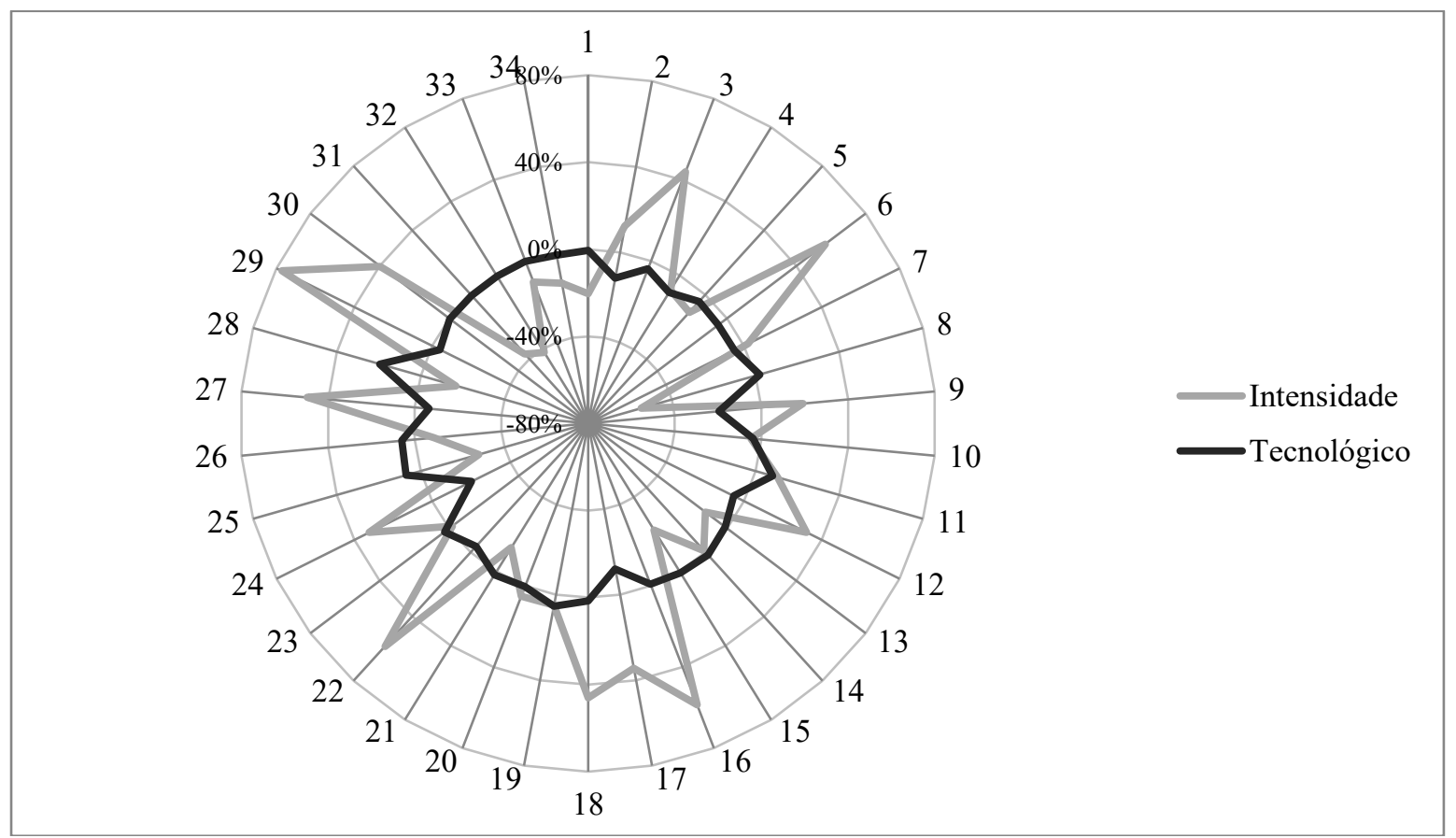

Fonte: Elaboração própria, com base nos dados de WIOD (2016).

Figura 6 - Impacto do fator demanda na variação do rendimento dos trabalhadores de qualificação média no Brasil entre 2005 e 2009 , por setor

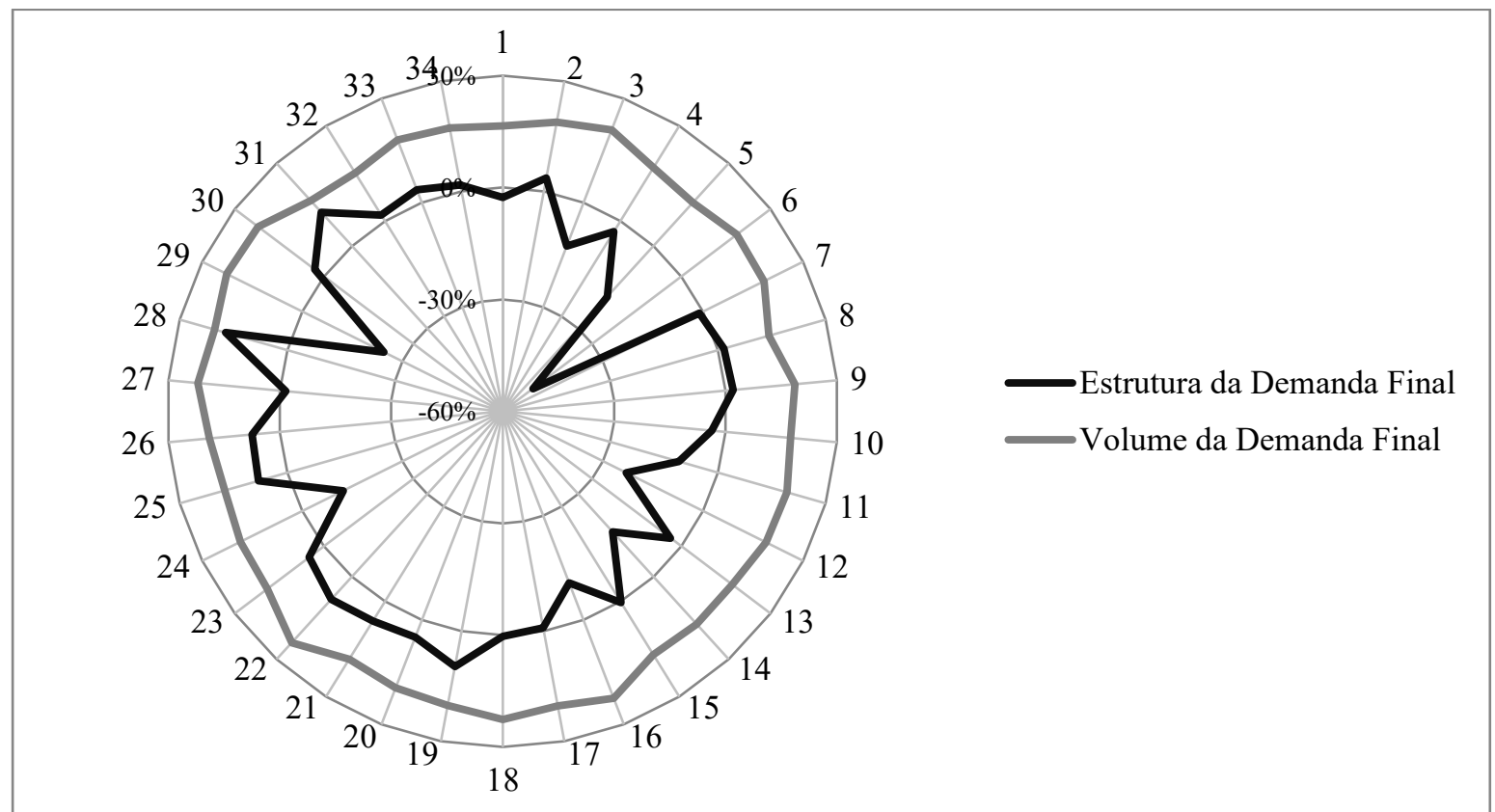

Fonte: Elaboração própria, com base nos dados de WIOD (2016). 
Figura 7 - Impacto do fator tecnológico na variação do rendimento dos trabalhadores de baixa qualificação no Brasil entre 2005 e 2009 , por setor

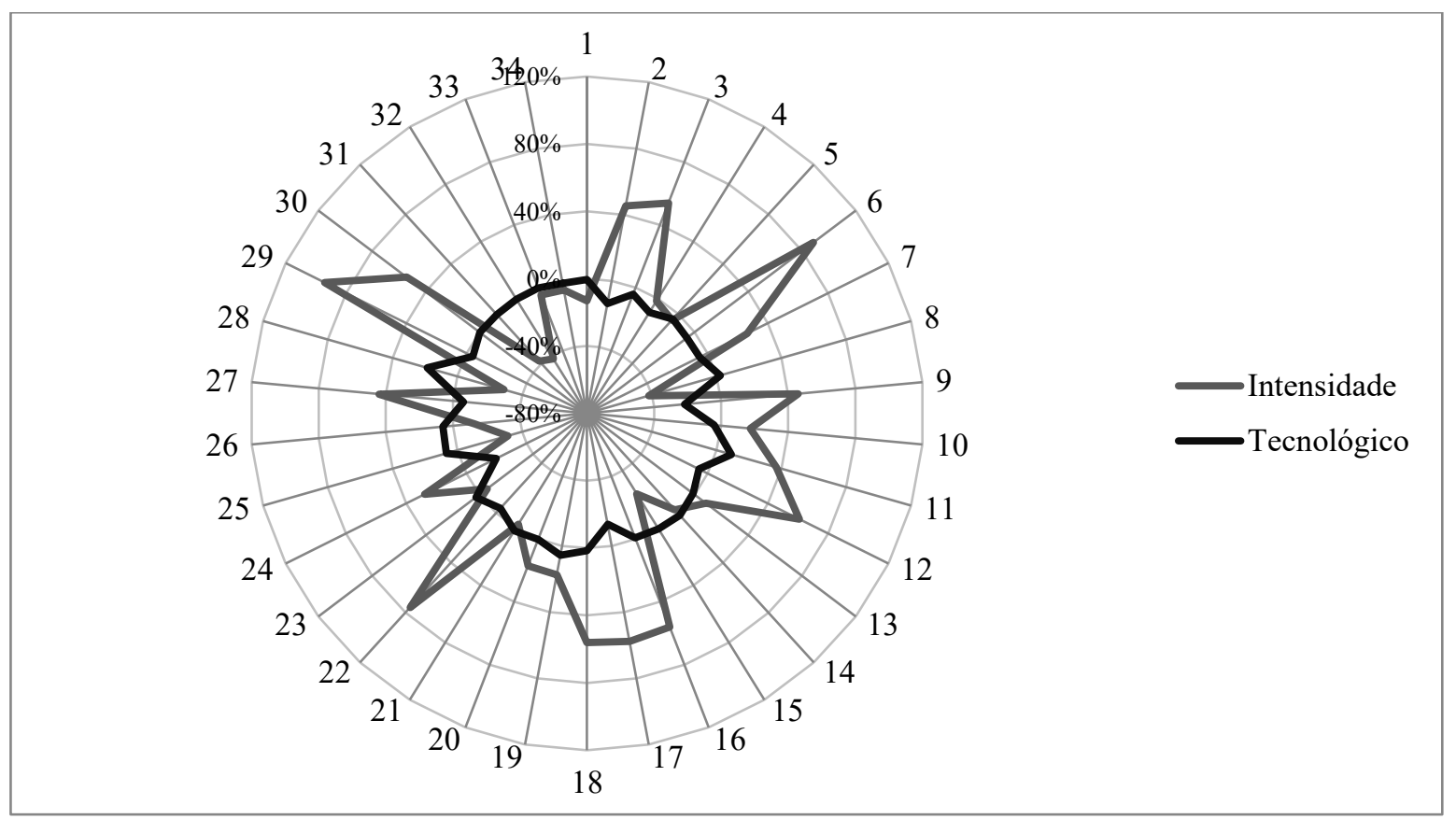

Fonte: Elaboração própria, com base nos dados de WIOD (2016)

Figura 8 - Impacto do fator demanda na variação do rendimento dos trabalhadores de baixa qualificação no Brasil entre 2005 e 2009 , por setor

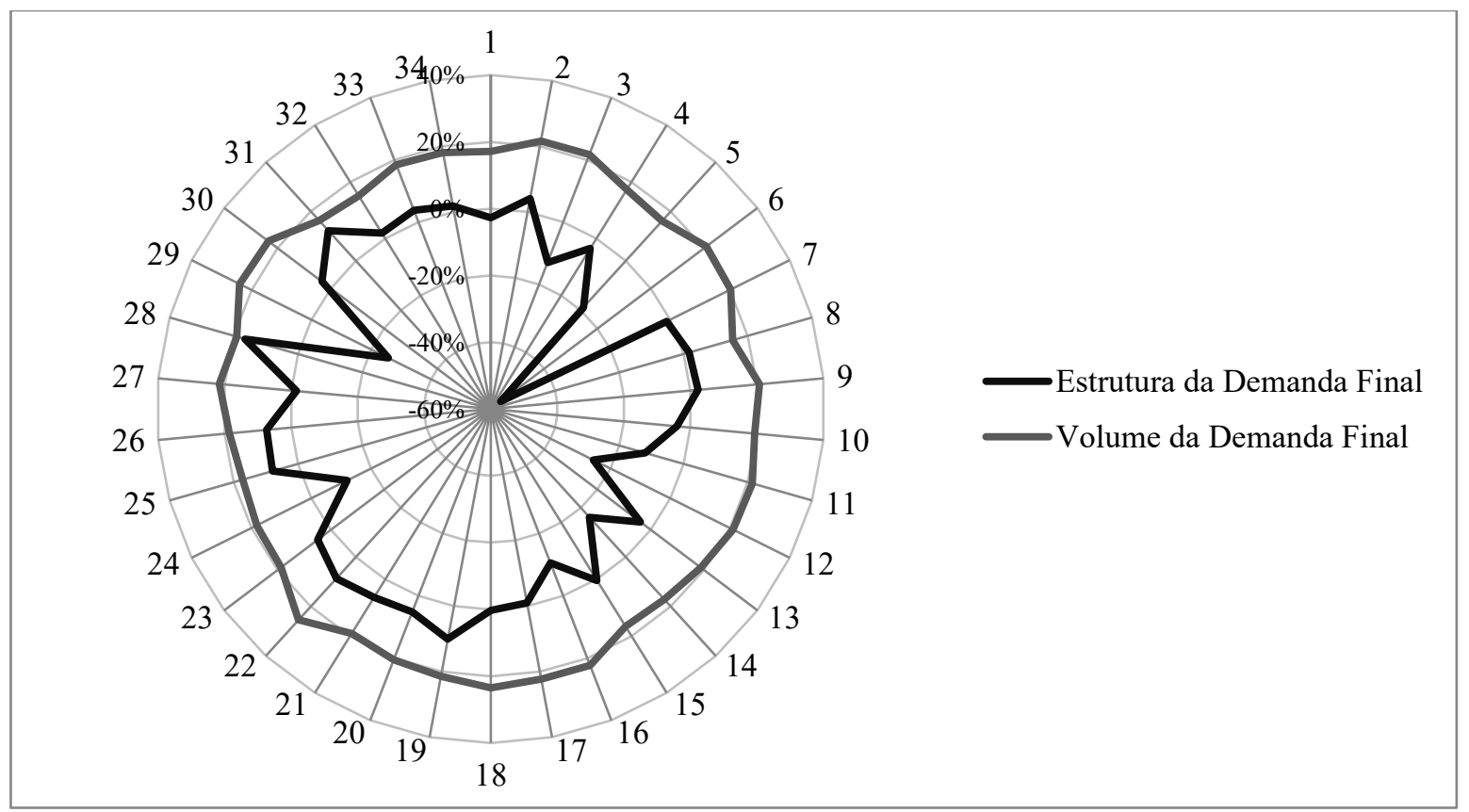

Fonte: Elaboração própria, com base nos dados de WIOD (2016)

Novamente, o fator demanda apresentou variações, em sua maioria, positivas, com predominância do efeito volume da demanda final sobre o efeito estrutura da demanda final, como é mostrado na Figura 6. Portanto, os resultados encontrados nos extrato de maior especialização continuam válidos entre os trabalhadores de especialização média: o aumento da demanda final impulsionou o rendimento do trabalho, sendo este, por vezes amplificado, e por vezes contrabalanceado pelo efeito intensidade. 
Contrariando os resultados anteriores, no extrato de trabalhadores com menor grau de especialização, o fator tecnológico foi positivo para a maior parte dos setores (19 entre os 34 setores apresentaram ganhos de rendimento devido à retrocessos na produtividade dos fatores). Em comum com os demais resultados, está a menor variação decorrente do efeito tecnológico, e os valores mais dispersos do efeito intensidade

Estes dados estão detalhados na Figura 7. Importante ressaltar que os maiores ganhos de rendimento observado entre os trabalhadores menos qualificados parecem ser decorrentes do efeito intensidade mais favorável a este grupo. Uma explicação plausível para este fato é que as políticas de valorização do salário mínimo, ao gerar um ganho de rendimento entre os menos qualificados provocam um aumento na relação rendimento por hora / produto, e consequentemente, uma acréscimo no efeito intensidade.

Por fim, o fator de alteração na demanda final influenciou o rendimento médio dos trabalhadores de menor qualificação de forma semelhante aos trabalhadores dos demais extratos: variações predominantemente positivas e lideradas pelo efeito volume da demanda final, como visto na Figura 8. Dessa forma, o padrão encontrado no fator demanda permanece intacto, isto é, o crescimento da economia na segunda metade da década de 2000 influenciou o rendimento médio do trabalho de forma relativamente homogênea, seja entre trabalhadores com diferentes qualificações, seja entre os diferentes setores da economia.

\section{Considerações Finais}

A técnica da decomposição estrutural permitiu compreender os fatores responsáveis pela variação dos rendimentos do trabalho encontradas no período 2005-2009 entre os trabalhadores de diferentes qualificações.

Como visto, os rendimentos variaram principalmente devido a dois efeitos: o efeito intensidade, do fator tecnológico, e o efeito estrutura da demanda final, do fator de demanda final. O primeiro destes efeitos está relacionado a alterações de produtividade dos fatores da economia. A maior sensibilidade deste efeito é, portanto, devida aos diferentes ganhos (ou perdas) de produtividade intersetorial, como observado também nos trabalhos de Langoni (1973) e Sesso Filho et al (2010). O segundo efeito, por sua vez, está vinculado ao crescimento da demanda final no período, e desta forma, como era esperado, beneficiou a todos os setores de forma mais uniforme.

Já os resultados avaliados segundo os extratos de especialização não diferem entre si de modo muito acentuado. Enquanto o fator demanda apresentou comportamento bastante semelhante entre os três grupos, o fator tecnológico caminhou de maneira mais errática, criando vieses mais positivos entre os trabalhadores de menor qualificação, elucidando o fato de este grupo apresentar, em média, maiores variações em seus rendimentos.

Importante destacar que os resultados apresentados neste trabalho corroboram com os fatos apresentados em estudos anteriores, como em Ferreira e Litchfield (2000), relacionados à possibilidade de queda das desigualdades em períodos de maior crescimento. Como observado, o efeito volume de demanda final foi o de maior preponderância na explicação das variações positivas nos rendimentos. Tendo em vista que este fator está diretamente relacionado ao crescimento econômico, observa-se o mesmo possui um efeito homogêneo sobre a economia. Conjuntamente, o efeito intensidade, responsável principal pela queda nas disparidades de rendimentos, configura-se como uma evidência da efetividade das políticas de valorização do salário mínimo, ao elevar a relação salário hora / produto dos menos qualificados.

Demonstra-se assim a compatibilidade, e não o trade-off, entre crescimento e distribuição e conclui-se que a decomposição estrutural consegue captar as transformações que o mercado de trabalho brasileiro vem passando, possibilitando a desagregação destas transformações em diferentes fatores e permitindo a melhor compreensão destas.

\section{Referências}

ALESINA, A.; RODRIK, D. Distributive politics and economic growth. Quarterly Journal of Economics, v. CIX, n. 2, p. 465-490, 1994.

ARRIGHI, G. A ilusão do desenvolvimento. Rio Janeiro, Vozes, 1997.

BANCO MUNDIAL. World Development Report 2006: Equity and Development. Washington, D.C: The World Bank and Oxford University Press, 2005

BARROS, R. P. de.; CARVALHO, M.; FRANCO, S.; MENDONÇA, R. Consequências e causas imediatas da queda recente da desigualdade de renda brasileira. IPEA, 2006.

BARROS, R. P. de., CORSEUIL, C. H. ; CURY, S. Salário mínimo e pobreza no brasil: uma abordagem de equilíbrio geral. Pesquisa e Planejamento Econômico v. 30, 157-182, 2000. 
BARROS, R. P. de; MENDONÇA, R. S. P. Os determinantes da desigualdade no Brasil. Economia Brasileira em Perspectiva. Rio de Janeiro: IPEA, p. 421-474, 1996.

BÉNABOU, R. Unequal societies. NBER Working Paper, n. 5.583, 1996 .

BONELLI, R.; SEDLACEK, G. L. Distribuição de renda: evolução no último quarto de século. In: SEDLACEK, G. L.; BARROS, R. P. de. Mercado de trabalho e distribuição de renda: uma coletânea. Rio de Janeiro: IPEA, 1989 (Série Monográfica, 35).

DIETZENBACHER, E.; LOS, B. Structural decomposition analysis with dependent determinants. In: Conference on Input Output Techniques, 13, 2000, Macerata. Anais Eletrônicos. Macerata, 2000. Disponível em: <http://policy.rutgers.edu/ cupr/iioa/iioa.htm>. Acesso em:20 maio 2016.

FERREIRA, F. H. G.; BARROS, R. P. de. The slippery slope: explaining the increase in extreme poverty in urban Brazil, 1976-1996. Rio de Janeiro: Departamento de Economia da PUC, 1999 (Texto para Discussão, 404).

FERREIRA, F. H. G.; LEITE, P. G. ; LITCHFIELD, J. A. The rise and fall of Brazilian inequality: 1981-2004. World Bank Policy Research Working Paper, 2006.

FERREIRA, F. H. G.; LITCHFIELD, J. A. Growing apart: inequality and poverty trends in Brazil in the 1980s. London: LSE - STICERD - DARP, Aug. 1996 (Discussion Paper, 23).

FERREIRA, F. H. G.; LITCHFIELD, J. A.. Educacion o inflacion?: explicando la desigualdad en Brasil en la decada de los ochenta. In: CÁRDENAS, M., LUSTIG, N. (eds.). Ch. 5. Pobreza y desigualdad en America Latina. Bogota: Tercer Mundo Editores, 1999.

FERREIRA, F. H. G.; LITCHFIELD, J. A. Os determinantes da desigualdade de renda no Brasil: luta de classes ou heterogeneidade educacional?. In: Ricardo Henriques. (Org.). Desigualdade e Pobreza no Brasil. Brasília: IPEA, $2000, v$. , p. 49-80.

FIRPO, S. ; REIS, M. C. Minimum wage effects on labor earnings inequality: some evidence from Brazil. XXVIII Encontro Brasileiro de Econometria. Salvador, 2006.

FISHLOW, A. Brazilian size distribution of income. The American Economic Review, v. 62, n. 1/2, p. 391-402, 1972.

HARVEY, D. A condição pós-moderna. Uma pesquisa sobre a origem da mudança cultural. São Paulo, Edições Loyola, 1992.

HOFFMAN, Rodolfo. Evolução da distribuição da renda no Brasil, entre pessoas e entre familias, 1979/86. In: GL Sedlacek and R. Paes de Barros. Mercado de trabalho e distribuição da renda: uma coletânea. Serie monográfica, n. $35,1989$.

KUPFER, D.; FREITAS, F. Análise estrutural da variação do emprego no Brasil entre 1990 e 2001. Boletim de Conjuntura, Instituto de Economia da UFRJ, Rio de Janeiro, p. 1-6, mar. 2004.

LAM, D.; DURYEA, S. Effects of schooling on fertility, labor supply, and investments in children, with evidence from Brazil. Journal of Human Resources, p. 160-192, 1999.

LANGONI, C. G. Distribuição da renda e desenvolvimento econômico do Brasil. Rio de Janeiro: Expressão e Cultura, 1973.

LEONTIEF, W. A Análise de Insumo-Produto. São Paulo: Abril Cultural, 1983.

MELLO e SOUZA, A. (1979). "Financiamento de educação e acesso a escola no Brasil", Coleção Relatórios de Pesquisa, n. O 42, IPEAIINPES, Rio de Janeiro.

PERSSON, T.; TABELLINI, G. Is inequality harmful for growth? American Economic Review, v. 84, n. 3, p. 600-621, 1994. 
POLLERT, Anna. Dismantling flexibility. Capital \& class, v. 12, n. 1, p. 42-75, 1988.

RAMOS, L. A distribuição de rendimentos no Brasil: 1976/85. Rio de Janeiro: IPEA, 1993.

RODRIK, D. Where did all the growth go? External shocks, social conflict, and growth collapses. Cambridge, MA: Kennedy School, Harvard University, 1997.

SEDLACEK, G. L.; BARROS, R. P. de. Mercado de trabalho e distribuição de renda: uma coletânea. Rio de Janeiro: IPEA, 1989 (Série Monográfica, 35).

SEGNINI, L.R.P, Educação e Trabalho: uma relação tão necessária quanto insuficiente. São Paulo Perspec. vol.14 no.2, São Paulo Apr./June 2000.

SESSO FILHO, U. A.; RODRIGUES, R. L.; MORETTO, A. C.; BRENE, P. R. A.; LOPES, R. L. Decomposição estrutural da variação do emprego no Brasil, 1991-2003. Economia Aplicada, v. 14, p. 99-123, 2010.

SOARES, S. S. D. Distribuição de renda no Brasil de 1976 a 2004 com ênfase no período de 2001 a 2004. Brasília: IPEA, 2006 (Texto para Discussão no 1166).

WIOD - World Input-Output Database. Disponível em: <http://www.wiod.org/>. Capturado em: 30/06/2016.

YMAI, A. K. Decomposição estrutural do emprego e da renda no Brasil: Uma análise de insumo-produto - 1990 a 2007. Dissertação de Mestrado, Programa de Pós-Graduação em Economia Regional, Universidade Estadual de Londrina, Londrina, 2010.

\section{Anexos}

Anexo 1 - Número de Identificação dos Setores

\begin{tabular}{|c|c|}
\hline $\begin{array}{l}\text { Número de } \\
\text { Identificação }\end{array}$ & Setor \\
\hline & Agricultura e Extrativismo \\
\hline 1 & Agricultura, Caça, Silvicultura e Pesca \\
\hline 2 & Extração Mineral \\
\hline & Indústria \\
\hline 3 & Alimentos, Bebidas e Tabaco \\
\hline 4 & Têxtil e Produtos Têxteis \\
\hline 5 & Couro e Calçado \\
\hline 6 & Madeira e Produtos de Madeira e Cortiça \\
\hline 7 & Celulose, Papel, Impressão e Editoração \\
\hline 8 & Coque, Refino de Petróleo e Combustível Nuclear \\
\hline 9 & Química e Produtos Químicos \\
\hline 10 & Borracha e Plástico \\
\hline 11 & Outros Minerais Não Metálicos \\
\hline 12 & Metais Básicos e Metais Fabricados \\
\hline 13 & Maquinário não especificado anteriormente \\
\hline 14 & Equipamento Óptico e Elétrico \\
\hline 15 & Equipamento de Transporte \\
\hline 16 & Manufatura não especificada anteriormente; Reciclagem \\
\hline 17 & Eletricidade, Gás e Fornecimento de Água \\
\hline
\end{tabular}


Anexo 1 Continuação...

\begin{tabular}{|c|c|}
\hline 18 & Construção \\
\hline $\begin{array}{l}\text { Número de } \\
\text { Identificação }\end{array}$ & Setor \\
\hline & Comércio e Serviço \\
\hline 19 & $\begin{array}{l}\text { Venda, Manutenção e Reparo de Veículos Motorizados e } \\
\text { Motocicletas; Varejo de Combustíveis }\end{array}$ \\
\hline 20 & $\begin{array}{l}\text { Vendas Comissão em Atacado, Exceto Veículos Motorizados e } \\
\text { Motocicletas }\end{array}$ \\
\hline 21 & $\begin{array}{c}\text { Vendas no Varejo, Exceto Veículos Motorizados e Motocicletas; } \\
\text { Reparo de Bens Domésticos }\end{array}$ \\
\hline 22 & Hotéis e Restaurantes \\
\hline 23 & Transporte Terrestre \\
\hline 24 & Transporte Aquático \\
\hline 25 & Transporte Aéreo \\
\hline 26 & $\begin{array}{c}\text { Outras Atividades de Auxílio ao Transporte; Atividades de } \\
\text { Agências de Viagem }\end{array}$ \\
\hline 27 & Correio e Telecomunicações \\
\hline 28 & Intermediação Financeira \\
\hline 29 & Atividades Imobiliárias \\
\hline 30 & $\begin{array}{l}\text { Aluguel de Máquinas e Equipamentos e Outras Atividades de } \\
\text { Negócios }\end{array}$ \\
\hline 31 & Administração Pública e Defesa; Seguridade Social Compulsória \\
\hline 32 & Educação \\
\hline 33 & Saúde e Serviço Social \\
\hline 34 & Outros Serviços Comunitários, Sociais e Pessoais \\
\hline
\end{tabular}

